\title{
Preoperative CT Colonoscopy for Esophageal Reconstruction with Colonic Interposition.
}

Prasit Mahawongkajit ( $\nabla$ prasit_md@yahoo.com )

Thammasat University Faculty of Medicine

Nuttorn Boochangkool

Thammasat University Faculty of Medicine

Research article

Keywords: CT colonoscopy, colonoscopy, colonic interposition, esophageal cancer, corrosive esophageal injury

Posted Date: February 12th, 2020

DOl: https://doi.org/10.21203/rs.2.23285/v1

License: (c) (1) This work is licensed under a Creative Commons Attribution 4.0 International License. Read Full License 


\section{Abstract}

\section{Background}

Colonic evaluation is an essential step before proceeding with esophagectomy to reconstruct by colonic interposition. Colonoscopy is the standard practice for colorectal cancer screening, but it has a chance of failing cecal intubation and carries a risk of horrific complication by colonic perforation. CT colonography is a less invasive alternative method that has been reported as useful for colonoscopic screening in cases of average risk of colorectal cancer. This study set out to report our clinical experience and to evaluate CT colonoscopy in the preoperative process for colonic interposition of esophagectomy patients.

Methods

Data for esophagectomy with colonic interposition patients between March 2016 and December 2019 was retrospectively analyzed.

Results

Nineteen patients were included in this study with 13 in the esophageal cancer group and 6 in the corrosive esophageal injury group. The majority of conduits used ileocolonic graft. After colonic interposition, endoscopy was performed and no lesions of conduits were detected.

Conclusion

CT colonoscopy is a minimally invasive and reliable colonic evaluation method for the patient of average colorectal cancer risk who has undergone esophagectomy with colonic interposition.

\section{Background}

Two esophageal diseases, namely esophageal cancer and corrosive esophageal injury are significant health problems worldwide, especially in a developing country such as Thailand (1-6). Esophagectomy is the leading surgical procedure in many accepted cancer treatment guidelines (7-9), for corrosive esophageal stricture and for esophageal perforation $(10,11)$. Colonic interposition is one of the reconstruction options after esophagectomy for these conditions $(12,13)$.

Colonic evaluation is an essential step before proceeding with esophagectomy to reconstruct by colonic interposition, particularly in a patient who has a high risk for colorectal cancer or is more than 50 years old. Colonoscopy is the standard practice for colorectal cancer screening by direct visualization of the intraluminal mucosa. However, it has a chance of failing cecal intubation $(14,15)$ and carries the risk of horrific complications by colonic perforation (16). CT colonography is a less invasive alternative method that is reported to be useful for colonoscopic screening in cases of average risk of colorectal cancer $(17,18)$. This study aimed to report our clinical experience and to evaluate CT colonoscopy in the preoperative process for colonic interposition of esophagectomy patients. 


\section{Methods}

We conducted a retrospective study with the esophagectomy patients between March 2016 and December 2019 who were identified in our hospital electronic documentation system. This study passed the institutional review board and ethical research process from Human Ethics Committee of Thammasat University (Faculty of Medicine) with reference number MTU-EC-SU-0-175/62.

In this study, the esophageal cancer patients were treated following the National Comprehensive Cancer Network (NCCN) (7) and the Japan Esophageal Society (8,9). An indication of esophagectomy was made by the gastrointestinal tumor board which had treating oncologists, diagnostic radiologists, radiation oncologists, and upper gastrointestinal surgeons as members.

For corrosive injury in our study, the surgical candidate patients consisted of a perforated caustic injury with previous esophagectomy, and post corrosive stricture with unsuccessful esophageal dilation. This group of patients obtained nutritional support by feeding jejunostomy and underwent the operation after corrosive ingestion episode within 6 to 8 months period.

The surgical plan for the conduit and reconstruction route was made by the patients and their families with an upper gastrointestinal surgeon. The patients who received a gastric tube, whole stomach, and jejunal graft for reconstruction after esophagectomy were excluded and patients with a high risk of colorectal cancer were excluded from this study. All of the patients who desired surgery with colonic interposition were assessed by preoperative CT colonoscopy for colonic evaluation and returned a negative finding of the colon. After surgery, endoscopy was performed for colonic conduit evaluation within three months. The data recorded patient characteristics, surgical procedures, postoperative courses, and outcomes. The collected data were analyzed and are presented descriptively using SPSS version 25 (SPSS Inc, Chicago, USA).

\section{Results}

Nineteen patients who were informed of colonic interposition procedures and consented to undergo surgery were included in this study with 13 patients in the esophageal cancer group and six patients in the corrosive esophageal injury group. The mean age was 57.6 years. There were 17 males and 2 females. The greater part of procedural indications was neoadjuvant followed by esophagectomy. Additional demographic data are presented in Table 1. 
Table 1

Characteristics of Patients treated by

Colonic Interposition.

\begin{tabular}{|lc|}
\hline Procedure, $\mathbf{n}$ & $\mathbf{n = 1 9}$ \\
\hline Age, mean \pm SD, years & $57.6 \pm 13.6$ \\
\hline Sex Male/Female & $17 / 2$ \\
\hline Indication, $\mathrm{n}(\%)$ & \\
\hline Esophageal cancer & \\
\hline - Neoadjuvant & $10(52.6)$ \\
\hline - Salvage & $3(15.8)$ \\
\hline Corrosive Esophageal injury \\
\hline - Stricture & $3(15.8)$ \\
\hline - Perforation & $3(15.8)$ \\
\hline
\end{tabular}

The majority of conduits used ileocolonic graft. All of the procedures included anastomosis at the left cervical area. Microvascular supercharging was done in $47.4 \%$ cases. Postoperative complications were: minor leakage $(n=2)$, anastomotic stricture $(n=2)$ and pneumonia $(n=3)$ without colonic conduit necrosis, surgical site infection, and 30-day mortality. After colonic interposition, endoscopic examination detected no lesions of conduits. Additional surgical procedures and outcomes of colonic interposition are presented in Table 2. 
Table 2

Surgical Procedures and Outcomes of Colonic Interposition.

\begin{tabular}{|ll|}
\hline Procedure, $\mathbf{n}$ & $\mathbf{n = 1 9}$ \\
\hline Conduit, $\mathrm{n}(\%)$ & $1(5.3)$ \\
\hline - Left side colon & $2(10.5)$ \\
\hline - Right side colon & $16(84.2)$ \\
\hline - ileocolonic & $9(47.4)$ \\
\hline Supercharge, n (\%) & \\
\hline Route, $\mathrm{n}(\%)$ & $10(52.6)$ \\
\hline - Substernal & $9(47.4)$ \\
\hline - Subcutaneous & \\
\hline Complication, $\mathrm{n}(\%)$ & $2(10.5)$ \\
\hline - Leakage & $0(0)$ \\
\hline - Necrosis & $2(10.5)$ \\
\hline - Stricture & $3(15.8)$ \\
\hline - Pneumonia & $0(0)$ \\
\hline - Surgical site infection & $0(0)$ \\
\hline 30-day mortality & $0(0)$ \\
\hline Detected lesion of colonic conduit from endoscopy & \\
\hline
\end{tabular}

\section{Discussion}

Esophagectomy is one of the most invasive surgical procedures in gastrointestinal surgery. The reconstruction operation is challenging for this group of patients. The surgeon has optional organs for reconstruction such as stomach, colon, and jejunum. Stomach used as a gastric tube or whole stomach is the most prevalent esophageal reconstruction conduit. However, for corrosive ingestion, some patients also have a gastric injury, especially for patients with a high grade of corrosive damage, and the addition of such an unexpected intraoperative situation if gastric conduit is not suitable, makes colon interposition play an essential role.

The colonic interposition could be performed by the left side, right side, and ileocolonic graft as the options for esophagectomy patients (3,19-22). Whatever the reconstruction, the quality of the colon should not be disregarded. Preoperative colonic evaluation is the crucial step in providing intraluminal mucosal information for the surgeon who is responsible for performing reconstruction operations upon 
this group of patients. The literature reports preoperative investigation for colonic interposition being done by colonoscopy and barium enema (20-22). CT colonoscopy is a minimally invasive technique for colonic screening while avoiding the perforation risk from the colonoscopy procedure and unsuccessful cecal intubation. The concerns around unexpected perforation from colonoscopy if it happens in an esophageal cancer patient, are that not only is patient suffering increased, but the operation might also be delayed and affect the treatment outcome. In addition to complete colonoscopy, especially cecal intubation, it is necessary to gain information for the right side and ileocolonic graft of this operation. In our study, we applied preoperative CT colonoscopy for the patients who were not a high risk of colorectal cancer and the results demonstrated it to be safe and effective for assessing the colon before colonic interposition. Endoscopy was performed in all cases after surgery within three months and could not identify mucosal abnormality of conduit that correlated with the result of preoperative CT colonoscopy.

For postoperative complications, previous studies including a larger number of patients reported anastomosis leakage $3-35 \%$, conduit necrosis $0-9 \%$, anastomotic stricture $6-19 \%$, wound infection $15.8-21 \%$, pulmonary complications $32.6-37 \%$ and 30 -day mortality $2.1-7.8 \%(3,19,20,22)$. Our study had comparable results of leakage and stricture with fewer pulmonary complications. The minor leakage patient was treated conservatively by feeding jejunostomy as nutritional support and closed within two weeks after diagnosis. The leakage patients had become stricture and were handled by balloon dilation. All of the patients with pneumonia were prescribed an intravenous broad-spectrum antibiotic. One patient required respiratory support. We did not find conduit necrosis, surgical site infection, and 30-day mortality in this study. However, any claims to be better or any clear conclusion cannot be made because of the small number of patients.

\section{Conclusions}

In this study, CT colonoscopy is a minimally invasive and reliable colonic evaluation method for the patient of average colorectal cancer risk who has undergone esophagectomy with colonic interposition. Further studies are required to assess and confirm this situation. We support preoperative CT colonoscopy as a favorable option in patients who are surgical candidates for esophagectomy and colonic interposition.

\section{Declarations}

\section{Ethics approval and consent to participate}

This study passed the ethical research process from Human Ethics Committee of Thammasat University (Faculty of Medicine) with reference number; MTU-EC-SU-0-175/62. The written informed consent was obtained from all participants in this manuscript

Author and co-authors confirm the study was submitted to and approved by institutional ethics committee and include a statement to this effect in the "Methods" and the "Ethics and Consent to 
Participate" sections of manuscript with ensure that the full name of ethics committee and institution is included in this statement.

Consent for publication Not Applicable

\section{Availability of data and material}

The datasets used and/or analysed during the current study available from the corresponding author on reasonable request.

\section{Competing interests}

Prasit Mahawongkajit and Nuttorn Boochangkool have nothing to disclose.

Funding

No funding was obtained for this study

\section{Authors' contributions}

PM and NB

All authors have read and approved the manuscript.

According to the ICMJE guidelines, to qualify as an author one should have:

1. a) made substantial contributions to conception and design, or acquisition of data, or analysis and interpretation of data; AND

2. b) been involved in drafting the manuscript or revising it critically for important intellectual content; AND

3. c) given final approval of the version to be published. Each author should have participated sufficiently in the work to take public responsibility for appropriate portions of the content; AND

4. d) agreed to be accountable for all aspects of the work in ensuring that questions related to the accuracy or integrity of any part of the work are appropriately investigated and resolved.

\section{Acknowledgment}

Special thanks to Norman Mangnall for assistance in editing the English version of this manuscript.

\section{References}

1. Bray F, Ferlay J, Soerjomataram I, Siegel RL, Torre LA, Jemal A. Global cancer statistics 2018: GLOBOCAN estimates of incidence and mortality worldwide for 36 cancers in 185 countries. CA Cancer J Clin. 2018;68(6):394-424.

2. Havanond C. Clinical features of corrosive ingestion. J Med Assoc Thai. 2003;86(10):918-24. 
3. Awsakulsutthi S, Havanond C. A retrospective study of anastomot- ic leakage between patients with and without vascular enhancement of esophageal reconstructions with colon interposition: Thammasat University Hospital experience. Asian J Surg. 2015;38(3):145-9.

4. Havanond $C$, Havanond P. Initial signs and symptoms as prognostic indicators of severe gastrointestinal tract injury due to corrosive ingestion. J Emerg Med. 2007;33(4):349-53.

5. Havanond $\mathrm{C}$. Is there a difference between the management of grade $2 \mathrm{~b}$ and 3 corrosive gastric injuries? J Med Assoc Thai. 2002;85(3):340-4.

6. Mahawongkajit P, Tomtitchong P, Boochangkool N, Limpavitayaporn P, Kanlerd A, Mingmalairak C, et al. Risk Factors for Esophageal Stricture in Grade 2b and 3a Corrosive Esophageal Injuries. J Gastrointest Surg. 2018 Oct;22(10):1659-64.

7. National Comprehensive Cancer Network. NCCN clinical practice guidelines in oncology: Esophageal and Esophagogastric junction Cancers, version 2[Internet]. Fort Washington, PA: National Comprehensive Cancer Network; 2019. https://www.nccn.org/professionals/physician_gls/PDF/esophageal.pdf Accessed Oct 12019.

8. Kitagawa Y, Uno T, Oyama T, Kato K, Kato H, Kawakubo H, et al. Esophageal cancer practice guidelines 2017 edited by the Japan Esophageal Society: part 1. Esophagus. 2019;16(1):1-24.

9. Kitagawa Y, Uno T, Oyama T, Kato K, Kato H, Kawakubo H, et al. Esophageal cancer practice guidelines 2017 edited by the Japan Esophageal Society: part 2. Esophagus. 2019;16(1):25-43.

10. Harlak A, Yigit T, Coskun K, Ozer T, Mentes O, Gülec B, et al. Surgical treatment of caustic esophageal strictures in adults. Int J Surg. 2013;11(2):164-8.

11. Dray X, Cattan P. Foreign bodies and caustic lesions. Best Pract Res Clin Gastroenterol. 2013;27(5):679-89.

12. Brown J, Lewis WG, Foliaki A, Clark GWB, Blackshaw GRJC, Chan DSY. Colonic Interposition After Adult Oesophagectomy: Systematic Review and Meta-analysis of Conduit Choice and Outcome. J Gastrointest Surg. 2018;22(6):1104-11.

13. Fisher RA, Gossage J, Griffiths E. Response to: "Colonic Interposition After Adult Oesophagectomy: Systematic Review and Meta-analysis of Conduit Choice and Outcome". J Gastrointest Surg. 2018;22(11):2002.

14. Aslinia F, Uradomo L, Steele A, Greenwald BD, Raufman JP. Quality assessment of colonoscopic cecal intubation: an analysis of 6 years of continuous practice at a university hospital. Am J Gastroenterol. 2006;101(4):721-31.

15. Park HJ, Hong JH, Kim HS, Kim BR, Park SY, Jo KW, et al. Predictive factors affecting cecal intubation failure in colonoscopy trainees. BMC Med Educ. 2013;13:5.

16. Rai V, Mishra N. Colonoscopic Perforations. Clin Colon Rectal Surg. 2018;31(1):41-46.

17. Martín-López JE, Beltrán-Calvo C, Rodríguez-López R, Molina-López T. Comparison of the accuracy of CT colonography and colonoscopy in the diagnosis of colorectal cancer. Colorectal Dis. 2014;16(3):082-9. 
18. IJspeert JE, Tutein Nolthenius CJ, Kuipers EJ, van Leerdam ME, Nio CY, Thomeer MG, et al. CTColonography vs. Colonoscopy for Detection of High-Risk Sessile Serrated Polyps. Am J Gastroenterol. 2016;111(4):516-22.

19. Mine S, Udagawa H, Tsutsumi K, Kinoshita Y, Ueno M, Ehara K, et al. Colon interposition after esophagectomy with extended lymphadenectomy for esophageal cancer. Ann Thorac Surg. 2009;88(5):1647-53.

20. Brown J, Lewis WG, Foliaki A, Clark GWB, Blackshaw GRJC, Chan DSY. J Gastrointest Surg. 2018;22(6):1104-11.

21. Bakshi A, Sugarbaker DJ, Burt BM. Alternative conduits for esophageal replacement. Ann Cardiothorac Surg. 2017;6(2):137-143.

22. Klink CD, Binnebösel M, Schneider M, Ophoff K, Schumpelick V, Jansen M. Operative outcome of colon interposition in the treatment of esophageal cancer: a 20-year experience. Surgery. 2010;147(4):491-6. 